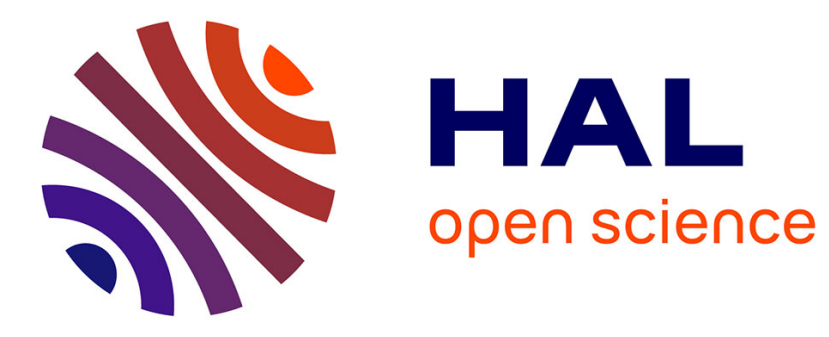

\title{
Measuring strain-induced crystallinity in rubbers from IR thermography
}

\author{
Jean-Benoit Le Cam
}

\section{To cite this version:}

Jean-Benoit Le Cam. Measuring strain-induced crystallinity in rubbers from IR thermography. 2018 Annual Conference on Experimental and Applied Mechanics, 2018, Paris, France. pp.57-62, 10.1007/978-3-319-95074-7_11. hal-02161136

\section{HAL Id: hal-02161136 \\ https://hal-univ-rennes1.archives-ouvertes.fr/hal-02161136}

Submitted on 7 May 2020

HAL is a multi-disciplinary open access archive for the deposit and dissemination of scientific research documents, whether they are published or not. The documents may come from teaching and research institutions in France or abroad, or from public or private research centers.
L'archive ouverte pluridisciplinaire HAL, est destinée au dépôt et à la diffusion de documents scientifiques de niveau recherche, publiés ou non, émanant des établissements d'enseignement et de recherche français ou étrangers, des laboratoires publics ou privés. 


\title{
Measuring Strain-Induced Crystallinity in Rubbers from IR Thermography
}

\author{
Jean-Benoît Le Cam
}

\begin{abstract}
The crystallinity of stretched crystallizable rubbers is classically investigated using X-ray diffraction (XRD). In the present study, we propose a new method based on temperature measurement and quantitative calorimetry to determine rubber crystallinity during mechanical tests as those carried out with conventional mechanical testing machines. For that purpose, heat power density are first determined from temperature variation measurements and the heat diffusion equation. The increase in temperature due to strain-induced crystallization (SIC) is then deduced from the heat power density by subtracting the part due to elastic couplings. The heat capacity, the density and the enthalpy of fusion are finally used to calculate the crystallinity from the temperature variations due to SIC. The characterization of the stress-strain relationship is not required. Furthermore, nonentropic contributions to rubber elasticity are taken into account if any. This alternative crystallinity measurement method is a user-friendly measurement technique, which is well adapted to most of the mechanical tests. It opens numerous perspectives in terms of high speed and full crystallinity field measurements.
\end{abstract}

Keywords Crystallinity $\cdot$ Strain-induced crystallization · Natural rubber · Infrared thermography $\cdot$ Calorimetry

\subsection{Introduction}

The strain-induced crystallization (SIC) of polymer, and especially of rubber, is classically investigated by using X-ray diffraction (XRD) [1]. Such measurement method provides information of importance on the crystalline phase structure [2-5], the chain orientation [6] and the kinetics of crystallization [7, 8]. To measure crystallinity, XRD requires specific equipment and tests conditions. Moreover, quantifying small crystallinity changes is difficult below 2\% [8]. To finish, in case of heterogeneous fields, each point of the crystallinity field is obtained successively, by scanning the zone under study [9-11] and the measurement zone is sometimes too large (for instance $300 \times 200 \mu \mathrm{m}^{2}$ in [10]) compared to the crystallinity gradient, typically at the crack tip of rubbers.

Developing an alternative measurement method could therefore be beneficial in many ways, typically for obtaining the crystallinity field instantaneously, at higher resolutions (temporal, spatial and on the value of the crystallinity) and with a conventional testing machine.

As SIC is well-known to be strongly exothermal, temperature or calorimetry measurements should be therefore a relevant alternative to determine the crystallinity. Indeed, in the 1970s Göritz and co-workers showed that crystallinity could be quantified accurately during stretching through calorimetric measurements [12]. Note that Boonstra was the first who suggested that crystallinity could be determined from the induced change in internal energy and the heat of fusion per repeating unit [13]. Using calorimetry is in the same line, because change in the internal energy can be taken into account with a "stretch calorimeter." Despite this, calorimetry under stretching was no longer used to measure crystallinity. Note that it has been nevertheless used to characterize the thermomechanical response and the intrinsic dissipation associated to the cyclic deformation of rubber [14-16].

Recently, Spratte et al. have taken up the idea that crystallinity $\chi$ can be measured from the thermal activity at the surface of rubber specimens [17]. Crystallinity was determined from the temperature change due to SIC $T_{\text {cryst }}$ by considering that the crystallization energy of natural rubber can be approximated by the enthalpy of fusion $\Delta H$ :

J. -B. Le Cam $(\bowtie)$

Univ Rennes, CNRS, IPR (Institute de Physique de Rennes) - UMR 6251, Rennes, France

LC-DRIME, Joint Research Laboratory, Cooper Standard - Institut de Physique UMR 6251, Rennes Cedex, France

e-mail: jean-benoit.lecam@univ-rennes1.fr 


$$
\chi(t)=\frac{\rho C T_{\text {cryst }}(t)}{\Delta H}
$$

$\rho$ and $C$ are the density and the heat capacity, respectively. They are assumed to be independent of strain and temperature.

In this approach, only two contributions to temperature changes were distinguished by the authors: crystallinity change and entropy change. Energetic effects were therefore neglected [18], while they can influence significantly the thermal response [19-25].

In the present study, crystallinity is determined from heat power density instead of temperature, by using infrared thermography during the mechanical tests. In practice, any temperature measurement technique such as a pyrometer can be used. This method takes intrinsically into account both the non-entropic (energetic) and the entropic contributions to rubber elasticity. Moreover, the measurement of the stress is not required. As this technique provides a full thermal field, crystallinity heterogeneity can be characterized, at several thousand frames per second, each value of the field being obtained at the same time. The methodology used to determine the crystallinity during rubber deformation is first presented. Then, it is applied to experimental data available in the literature for unfilled NR. Concluding remarks close the paper.

\subsection{Methodology for Measuring Crystallinity}

\subsubsection{Thermodynamical Framework}

Most of mechanical tests are conducted under non-adiabatic conditions. The temperature measured is therefore affected by heat diffusion during the tests, possible temperature gradients at the surface of the undeformed specimen and external heat sources (for instance radiations). Therefore, changes in temperature are not only due to the material deformation, and the heat diffusion equation is used to determine the corresponding heat power density from temperature measurement. This quantity is intrinsic to the material deformation. After some calculations that are not detailed here, the heat diffusion equation can be rewritten in case of homogeneous heat power density field [26]:

$$
s=\rho C\left(\dot{\theta}+\frac{\theta}{\tau}\right)
$$

where $\theta$ denotes the temperature variation $\left(T-T_{r e f}\right)$ with respect to the equilibrium temperature $T_{r e f}$ in the undeformed state. In the present case, $T_{r e f}$ is constant and equal to the ambient temperature. In case where changes in ambient temperature occur, $T_{r e f}$ has to be corrected accordingly. $\tau$ is a parameter characterizing the heat exchanges between the specimen and its surroundings. It can be easily identified from a natural return to room temperature after a heating (or a cooling) for each testing configuration (machine used, environment, stretch level, etc). Further details are provided in [27].

\subsubsection{Determination of the Crystallinity}

The methodology proposed is composed of 4 steps presented in the diagram in Fig. 11.1. Input data required are the temperature variation $\theta$, parameter $\tau$ and the thermo-physical parameters $\rho, C$ and $\Delta H$. The first step consists in calculating the heat power density by using Eq. 11.2. The typical calorific response of unfilled NR is illustrated by curve A. It exhibits a strong increase in the heat power density when crystallization starts. $\lambda_{c}$ and $\lambda_{m}$ are the stretches at which SIC starts and melting is complete, respectively. Step 2 consists in predicting the heat power density due to elastic couplings only by using a polynomial form $\left(C_{1}\left(I_{1}-3\right)+C_{2}\left(I_{1}-3\right)^{2}+C_{3}\left(I_{1}-3\right)^{3}\right)$. The thermal energy due to SIC is indeed the area located between the heat power density (curve A) and the part of the heat power density due to elastic couplings (curve B). The latter is not known once crystallization starts, but is known before. In the present study, we assume that the elastic couplings evolve in a similar way after crystallization starts. $C_{1}, C_{2}$ and $C_{3}$ are identified from the experimental heat power density before SIC starts. The heat power density due to SIC (A-B) is then computed in Step 3 for determining the temperature variation due to SIC $T_{\text {cryst }}$. Here, the numerical scheme is not centered, another numerical scheme can be used. The last step consists in calculating the crystallinity by applying Eq. 11.1. This method is very simple and does not require measuring the nominal stress variations nor characterizing possible non-entropic effects. 


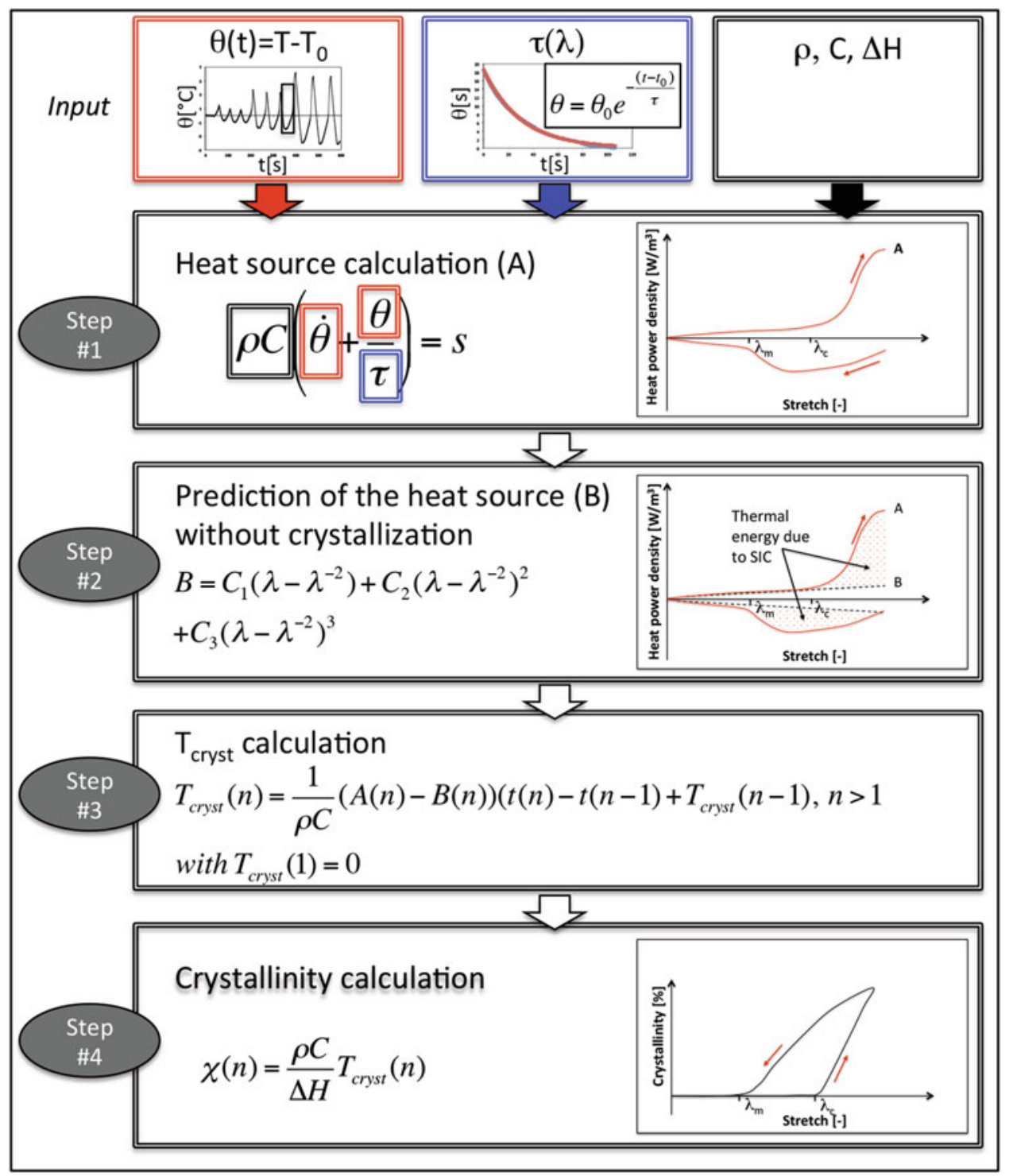

Fig. 11.1 Methodology for determining crystallinity

\subsection{Application to an Unfilled Natural Rubber}

The methodology proposed for measuring crystallinity is now applied to experimental data issued from the literature [27, 28], obtained with an unfilled natural rubber submitted to cyclic uniaxial tensile loading. The mechanical loading applied corresponded to four sets of three cycles at a maximum stretch of 2, 5,6 and 7.5 at $\pm 100 \mathrm{~mm} / \mathrm{min}$. It is presented in Fig. 11.2.

The stretch is defined as the ratio of the current length over the initial length. $\rho$ and $C$ are equal to $936 \mathrm{~g} / \mathrm{dm}^{3}$ and $1768 \mathrm{~J} /(\mathrm{kg} \cdot \mathrm{K}) . \tau$ depends on the stretch and is defined as $\tau(\lambda)=40.48-3.25 \lambda$. Figure 11.3 depicts the heat power density in relation to the stretch. The heat power density is determined from the temperature measurements (Step \#1) and appears in red color. It is due to elastic couplings and SIC effects. During loading (unloading), the heat power density is positive (negative) and increases (decreases) with the stretch. Once SIC starts, the heat power density evolution for loading and unloading are no longer symmetrical. During loading, the heat power density evolves in a quasi-linear manner until a stretch close to 4 is reached. A dissymmetry is observed for stretches higher than 4; the stretch level at which SIC starts. During unloading, the heat power density rate first increases in absolute value until reaching a stretch equal to 4 , is constant until a stretch equal to 3.5 is reached, and then decreases.

The heat power density due to elastic couplings only, i.e. without accounting for SIC effects, is predicted with a polynomial form (Step \#2) and appears in black color. The thermal energy due to SIC is the area located between the heat power density 


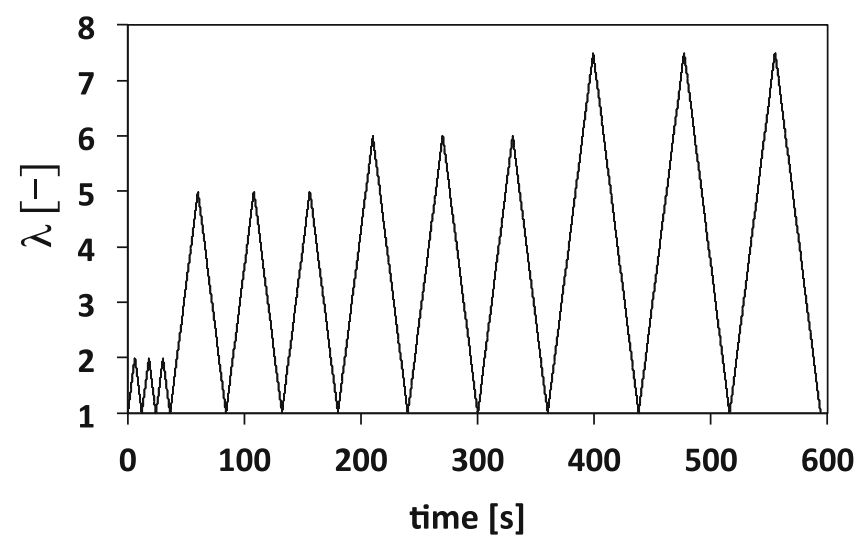

Fig. 11.2 Mechanical loading

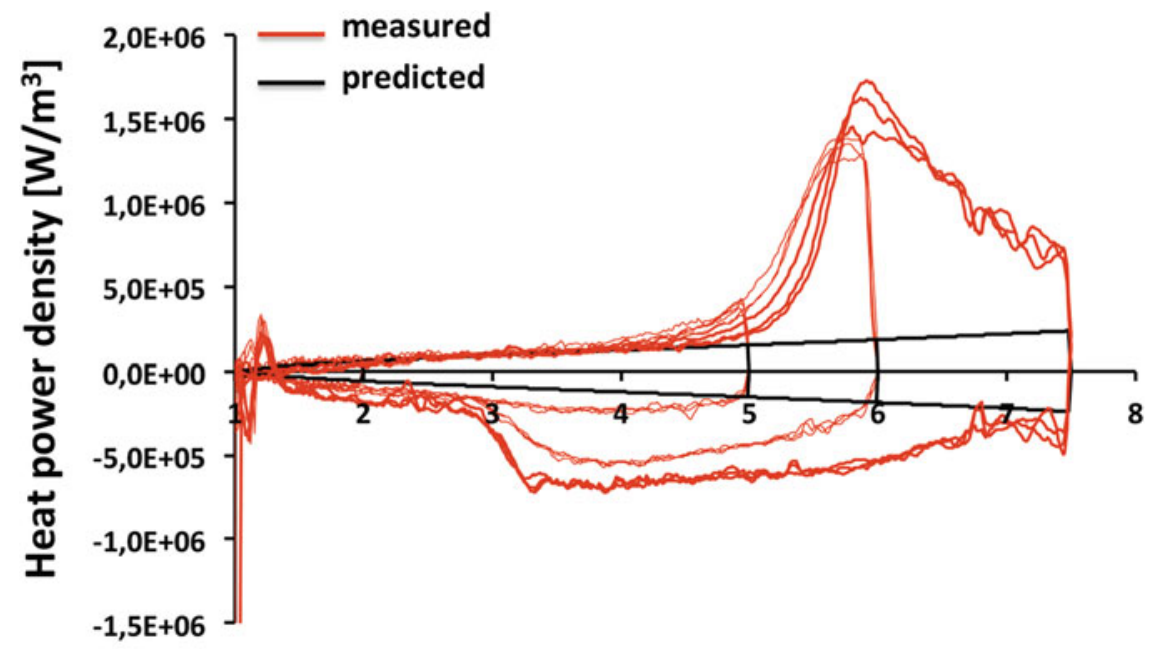

Stretch [-]

Fig. 11.3 Heat power density (in red) and predicted heat power density due to elastic couplings (in black) in relation to the stretch

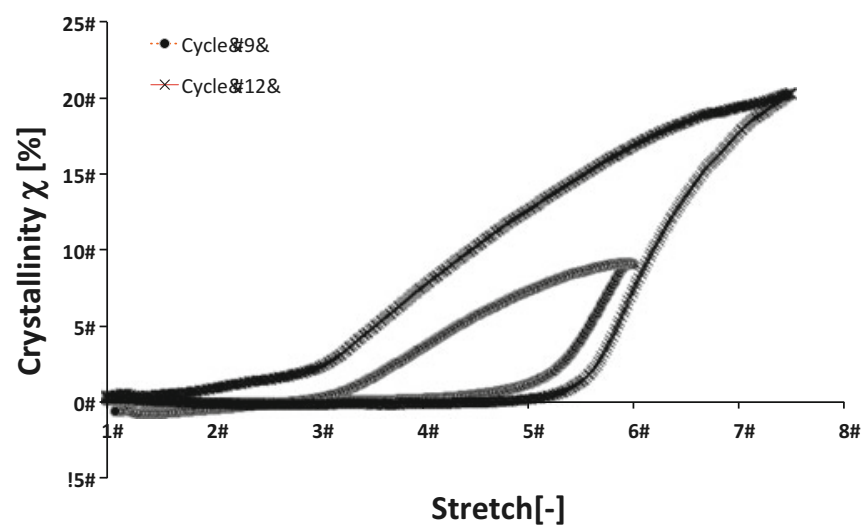

Fig. 11.4 Temperature change due to crystallinity in relation to the stretch (Step \#4)

measured (curve A in Fig. 11.1) and the predicted part of the heat power density curve due to elastic couplings (curve B). The difference between the two curves is used to calculate $T_{\text {cryst }}$ (Step \#3).

The results being the same for cycles conducted at the same maximum stretch, only cycles \#9 and \#12 at respectively $\lambda=6$ and $\lambda=7.5$ are presented in Fig. 11.4. The crystallinity is obtained by dividing $T_{\text {cryst }}$ by the enthalpy of crystallite fusion $\left(59.9 \mathrm{~J} / \mathrm{cm}^{3}\right.$, see [29]) and multiplying by the density and the heat capacity (Step \#4). The crystallinity versus stretch is given in Fig. 11.3. The comparison with results obtained from XRD will be discussed during the presentation. 


\subsection{Conclusion}

In this study, a new measurement technique is presented to determine the crystallinity in stretched crystallizing rubber using IR thermography. Temperature variation due to SIC is determined from the corresponding heat power density, i.e. due to SIC. Characterizing the stress-strain relationship as well as the non-entropic contributions to rubber elasticity is not required. It is therefore well adapted to characterize heterogeneous crystallinity field, i.e. where the stress-strain relationship is not known. Crystallinity obtained as a function of the stretch provides comparable results as those obtained by XRD measurements. The method proposed is therefore a realistic alternative, user-friendly and accurate, to measure crystallinity of stretched crystallizing rubbers from any temperature measurement technique and quantitative calorimetry. Furthermore, it is well adapted to most of the mechanical tests performed with conventional testing machine, which enables us to investigate the effect of SIC on fatigue resistance of rubber [15, 30, 31].

\section{References}

1. Katz, J.R.: Röntgenspektrographische Untersuchungen am gedehnten Kautschuk und ihre mögliche Bedeutung für das Problem der Dehnungseigenschaften dieser Substanz. Naturw. 4, 410-416 (1925)

2. Bunn, C.W.: Molecular structure and rubber-like elasticity. I. The crystal structures of Gutta-Percha, rubber and polychloroprene. Proc. R. Soc. London, Ser. 1. 180, 40-66 (1942)

3. Takahashi, Y., Kumano, T.: Crystal structure of natural rubber. Macromolecules. 37, 4860 (2004)

4. Immirzi, A., Tedesco, C., Monaco, G., Tonelli, A.E.: Crystal structure and melting entropy of natural rubber. Macromolecules. 38, 1223 (2005)

5. Rajkumar, G., Squire, J.M., Arnott, S.: A new structure for crystalline natural rubber. Macromolecules. 39, 7004 (2006)

6. Toki, S., Sics, I., Ran, S.F., Liu, L.Z., Hsiao, B.S., Murakami, S., Tosaka, M., Kohjiya, S., Poompradub, S., Ikeda, Y., Tsou, A.H.: Straininduced molecular orientation and crystallization in natural and synthetic rubbers under uniaxial deformation by in-situ synchrotron X-ray study. Rubber Chem. Technol. 77, 317-335 (2004)

7. Toki, S., Fujimaki, T., Okuyama, M.: Strain-induced crystallization of natural rubber as detected real-time by wide-angle x-ray diffraction technique. Polymer. 41, 5423-5429 (2000)

8. Trabelsi, S., Albouy, P.-A., Rault, J.: Effective local deformation in stretched filled rubber. Macromolecules. 36, $9093-9099$ (2003)

9. Brüning, K., Schneider, K., Roth, S.V., Heinrich, G.: Strain-induced crystallization around a crack tip in natural rubber under dynamic load. Polymer. 54(22), 6200-6205 (2013)

10. Rublon, P., Huneau, B., Verron, E., Saintier, N., Beurrot, S., Leygue, A., Mocuta, C., Thiaudière, D., Berghezan, D.: Multiaxial deformation and strain induced crystallization around a fatigue crack in natural rubber. Eng. Fract. Mech. 123, 59-69 (2014)

11. Demassieux, Q.: Structural changes in the process zone of a cyclic fatigue crack in filled natural rubber. PhD thesis, Université Pierre et Marie Curie (2016)

12. Göritz, D., Müller, F.H.: Die kalorimetrische Erfassung der Dehnungskristallisation Polymerer. Kolloid-Zeitschrift und Zeitschrift für Polymere. 241(20), 1075-1079 (1970)

13. Boonstra, B.B.S.T.: Some properties of vulcanized rubber under strain - degree of crystallization as calculated from temperature coefficient of elastic tension. Ind. Eng. Chem. 4(2), 3:362-3:365 (1951)

14. Samaca Martinez, J.R., Le Cam, J.B., Balandraud, X., Toussaint, E., Caillard, J.: New elements concerning the Mullins effect: a thermomechanical analysis. Eur. Polym. J. 55, 98-107 (2014)

15. Samaca Martinez, J.R., Balandraud, X., Toussaint, E., Le Cam, J.B., Berghezan, D.: Thermomechanical analysis of the crack tip zone in stretched crystallizable natural rubber by using infrared thermography and digital image correlation. Polymer. 55, 6345-6353 (2014)

16. Samaca Martinez, J.R., Balandraud, X., Toussaint, E., Le Cam, J.B., Berghezan, D.: Heat and strain measurements at the crack tip of filled rubber under cyclic loadings using full field techniques. Mech. Mater. 81, 62-71 (2015)

17. Spratte, T., Plagge, J., Wunde, M., Klueppel, M.: Investigation of strain-induced crystallization of carbon black and silica filled natural rubber composites based on mechanical and temperature measurements. Polymer. 115, 12-20 (2017)

18. Meyer, K.H., Ferri, C.: Sur l'élasticité du caoutchouc. Helv. Chim. Acta. 18, 570-589 (1935)

19. Wolf, F.P., Allen, G.: The energetic contribution to rubber elasticity in the range of small uniaxial compression and moderate elongation. Polymer. 16, 209-217 (1975)

20. Allen, G., Bianchi, U., Price, C.: Thermodynamics of elasticity of natural rubber. Trans. Faraday Soc. 59, 2493 (1963)

21. Allen, G., Kirkham, M.J., Padget, J., Price, C.: Thermodynamics of rubber elasticity at constant volume. Trans. Faraday Soc. 67, 1278 (1971)

22. Shen, M.C.: Internal energy contribution to the elasticity of natural rubber. Macromolecules. 2, 358-364 (1969)

23. Le Cam, J.-B.: Energy storage due to strain-induced crystallization in natural rubber: the physical origin of the mechanical hysteresis. Polymer. 127, 166-173 (2017)

24. Treloar, L.R.G.: The elasticity and related properties of rubbers. Rep. Prog. Phys. 36(7), 755 (1973)

25. Heinrich, G., Kaliske, M., Klüppel, M., Mark, J.E., Straube, E., Vilgis, T.A.: The thermoelasticity of rubberlike materials and related constitutive laws. J. Macromol. Sci. Part A. 40, 87-93 (2003)

26. Chrysochoos, A.: Analyse du comportement des matériaux par thermographie infra rouge. Colloque Photomécanique. 95, 201-211 (1995)

27. Samaca Martinez, J.R., Le Cam, J.-B., Balandraud, X., Toussaint, E., Caillard, J.: Mechanisms of deformation in crystallizable natural rubber. Part 2: quantitative calorimetric analysis. Polymer. 54, 2727-2736 (2013) 
28. Samaca Martinez, J.R., Le Cam, J.-B., Balandraud, X., Toussaint, E., Caillard, J.: Mechanisms of deformation in crystallizable natural rubber. Part 1: thermal characterization. Polymer. 54, 2717-2726 (2013)

29. Roberts, D.E., Mandelkern, L.: Thermodynamics of crystallization in high polymers. Natural rubber. Rubber Chem. Technol. 28(3), 718-727 (1955)

30. Le Cam, J.-B., Huneau, B., Verron, E.: Fatigue damage in carbon black filled natural rubber under uni- and multiaxial loading conditions. Int. J. Fatigue. 52, 82-94 (2013)

31. Le Cam, J.-B., Huneau, B., Verron, E., Gornet, L.: Description of fatigue damage in carbon black filled natural rubber. Fatigue Fract. Eng. Mater. Struct. 31(12), 1031-1038 (2008) 